\title{
A CONSTRUÇÃO DE UMA IDENTIDADE REGIONAL DE DEFESA PARA A AMÉRICA DO SUL: AGENDAS E DESAFIOS
}

\author{
Oscar Medeiros Filho ${ }^{1}$
}

é doutor em Ciência Política pela USP e oficial do exército. Brasilia, DF, Brasil.

E-mail: <oscarfilho@usp.br>.Telefone: (61)99121-4296

http://dx.doi.org/10.1590/ 0102-203220/101

Com o avanço do processo de integração regional, observado ao longo das duas últimas décadas, o conceito de "comunidade de segurança" foi incorporado aos discursos de defesa na América do Sul. Tal conceito, elaborado em meados do século XX, refere-se a uma região cujos membros têm real convicção de que os países que a compõem não combateriam entre si (Deutsch, 1966). Em outras palavras, seria a superação do "temível ambiente anárquico" em um sistema caracterizado pela relação entre atores soberanos. No campo das Relações Internacionais, o conceito desenvolvido por Karl Deutsch contém um elemento de originalidade no estudo de processos de cooperação entre Estados nacionais na medida em que aproxima, na arena interestatal, os conceitos de "segurança", "comunidade" e "vontade política". Os Estados fariam parte de uma comunidade de segurança por vontade própria fundamentada em uma racionalidade construída com base em uma percepção histórica da realidade.

\footnotetext{
${ }^{1}$ As opiniões contidas neste texto são de inteira responsabilidade do autor, não refletindo necessariamente o entendimento do Exército Brasileiro.
} 
Há controvérsias, entretanto, sobre o fato de a América do Sul corresponder ou não à tipologia deutschiana. Não é nosso objetivo entrar no mérito desse debate. Interessa-nos, aqui, discutir as ideias de agentes políticos que, incorporando o conceito de Deutsch em seus discursos, compreendem a região como tal.

Pensada em termos de comunidade de segurança, e considerando documentos e discursos de autoridades de defesa da região ao longo da primeira metade da década atual, este artigo busca analisar a viabilidade de implantação de uma estratégia de dissuasão extrarregional sul-americana, considerando a possibilidade de aprofundamento de uma identidade regional de defesa que permitisse o desenvolvimento de capacidades militares coletivas.

Para tanto, o artigo está estruturado em cinco seções. Inicialmente, será apresentada uma ressalva sobre os tipos de comunidades de segurança. Em seguida, será apresen204 tado um breve panorama do processo de integração regional sul-americano a partir da ótica brasileira. As seções três e quatro tratarão, respectivamente, de discursos de ministros de Defesa do Brasil e do diretor do Centro de Estudos Estratégicos de Defesa do Conselho de Defesa Sul-americano (CEED-CDS) da União de Nações Sul-americanas (Unasul). Por fim, será discutida a viabilidade da instrumentalização da ideia de dissuasão regional na América do Sul.

\section{Comunidades de segurança: tipos}

Para atender aos objetivos aqui propostos, faz-se necessário diferenciar dois tipos de "comunidades de segurança", conforme o grau de integração regional. Pode-se dizer que o nível mais simples de "comunidades de segurança" ocorre quando a cooperação tem por objetivo principal o estabelecimento da paz entre as unidades que a compõem. O segundo nível, mais aprofundado, ocorreria quando, além da paz entre os membros da comunidade, busca-se 
estabelecer uma identidade estratégica comum. O objetivo dos membros de uma comunidade definirá o nível de integração desejável: se o objetivo for somente a paz entre seus componentes, estaríamos diante de um modelo de comunidade de segurança pluralística; porém, se o objetivo refere-se a alguma forma de poder corporativo, como a defesa contra terceiros, por exemplo, então estaríamos diante de modelo amalgamado (Deutsch, 1982).

Assim, no domínio "amalgamado", o grau de integração e a consciência de unidade política seriam tão fortes que fariam surgir no seio do bloco uma consciência de unidade orgânica e de defesa conjunta. Nesse sentido, as regiões tenderiam a constituir "unidades supranacionais", colocando-se entre o nacional e o global.

De forma simplificada, pode-se falar, então, de dois tipos de comunidades de segurança: uma que envolve apenas a relação entre os membros da região ("para dentro"), e outra que, imaginando a região como um constructo supranacional, envolve a sua relação com terceiros ("para fora").

\section{A construção regional da América do Sul: um breve panorama}

A ideia de América do Sul como prioridade da política externa brasileira é algo relativamente recente. Em termos históricos, pode-se dizer que a segunda metade da década de 1970 inaugura o processo de "sul-americanização" do Brasil. O rompimento do modelo pan-americanista ${ }^{2}$ de nossa política externa ocorre de forma concomitante a uma acelerada "ofensiva diplomática” em direção à América do Sul.

Dois eventos parecem corroborar essa ideia: de um lado, o rompimento do Acordo Militar Brasil-Estados Unidos, em

\footnotetext{
2 Denominamos aqui "pan-americanista" o movimento liderado pelos Estados Unidos, ao longo do Século XX, de construção de uma identidade hemisférica, especialmente nos campos da defesa e da segurança.
} 
junho de $1977,{ }^{3}$ e, de outro, o estabelecimento do Tratado de Cooperação Amazônica (TCA), em julho de 1978, por iniciativa brasileira. De fato, à medida que o Brasil procurava se afastar da esfera geopolítica norte-americana, percebia-se um movimento no sentido contrário - de aproximação - especialmente em relação ao seu até então principal concorrente regional: a Argentina. A partir de 1979, com a assinatura do Tratado Tripartite Itaipu-Corpus entre Brasil e Argentina, diversos acontecimentos podem ser destacados, como a assinatura do Tratado de Assunção, em 1991, que originou o Mercosul; a primeira reunião de chefes de Estados da América do Sul, em setembro de 2000; e a assinatura do Tratado Constitutivo da Unasul em maio de 2008 estes últimos coincidentemente ocorridos em Brasília.

No que se refere estritamente à dimensão militar da integração regional, pode-se afirmar que esta ganhou impulso no início do Governo Lula. ${ }^{4}$ Três eventos relacionados a esse período merecem destaque. O primeiro diz res-

\footnotetext{
${ }^{3}$ Vale destacar dois aspectos importantes que marcaram esse contexto de rompimento com os EUA: a política de defesa dos direitos humanos do Governo Jimmy Carter e a suposta pressão para que o Brasil rompesse o acordo nuclear com a Alemanha.

${ }^{4}$ Antes do Governo Lula, várias outras iniciativas no campo da defesa ocorreram. Oficialmente, as primeiras propostas brasileiras para o desenvolvimento de um sistema de defesa sul-americano só começam a vir à tona com a criação do Ministério da Defesa, em 1999. Naquele ano, o então Ministro da Defesa Geraldo Quintão defendeu a ideia de uma estratégia regional sul-americana, promovendo "não a formação de alianças militares no sentido clássico, e sim o reforço do diálogo no nível da concepção de políticas de defesa" (Martins Filho, 2006, p. 21). Entretanto, a postura oficial dos militares brasileiros em relação ao tema da integração militar na América do Sul sempre foi marcada pela prudência e cautela. A visão geral dos militares brasileiros era a de que uma concepção de força supranacional permanente não atenderia aos interesses estratégicos do Brasil (Silveira, 2003). Apesar de buscar maior aproximação com outros exércitos, por meio do entendimento e da cooperação em áreas de interesse comum, os militares brasileiros consideravam inadequadas as propostas de organização de força de segurança supranacional, preferindo para isso acordos bilaterais (Amaral, 2004). De forma geral, predominava entre eles a percepção de que a integração constituiria um importante instrumento de projeção internacional para o Brasil, mas que, ao mesmo tempo, pela persistência de desconfianças mútuas entre os próprios países da região, não estariam dadas as condições para a integração militar na América do Sul (Medeiros Filho, 2010).
} 
peito à ideia do então Ministro da Defesa, José Viegas Filho, que vislumbrava o avanço da cooperação militar na América do Sul por meio de "uma maior interação entre as indústrias de material de emprego militar dos países [da América do Sul]" (Viegas Filho, 2003).

O segundo evento diz respeito ao documento Projeto Brasil 3 tempos: 50 temas estratégicos, elaborado em 2004 pelo Núcleo de Assuntos Estratégicos da Presidência da República (NAE), que cogitava a possibilidade de estabelecimento de um sistema coletivo de defesa regional.

O terceiro evento refere-se à proposta de criação do Conselho de Defesa Sul-americano (CDS), apresentada inicialmente em janeiro de 2006 durante uma reunião do presidente Lula com seus colegas da Venezuela (Hugo Chávez) e da Argentina (Néstor Kirchner), realizada em Brasília. Vale destacar que desde essa primeira reunião havia divergência sobre a finalidade do CDS entre seus proponentes: enquanto para o presidente Lula o foco era o desenvolvimento tecnológico regional no setor de Defesa e a institucionalização das reuniões dos ministros de defesa, para o presidente Chávez o projeto seria uma espécie de "Otan do Sul” (Medeiros Filho, 2010, p. 82).

Apesar de ter sido cogitada no início de 2006, a proposta de criação do CDS só foi retomada em outubro de 2007, quando o novo Ministro da Defesa, Nelson Jobim, encampou a ideia e resolveu percorrer, a partir do início de 2008, todos os países vizinhos em uma missão que ele mesmo intitulou de "diplomacia militar". Para Jobim, a criação do CDS, além de outros objetivos, possibilitaria maior intercâmbio de pessoal (formação e capacitação), a realização de exercícios militares conjuntos, a participação conjunta em missões de paz e a integração de bases industriais de defesa (Jobim, 2010a, p. 19).

Na opinião de Jobim, a integração regional constituiria fator essencial para a estabilidade e prosperidade do conjunto 
de países sul-americanos, de tal forma que não haveria como pensar uma estratégia de projeção brasileira sem se considerar um projeto sul-americano (Jobim, 2010a, p. 16).

A criação do CDS imprimiu certo ineditismo à geopolítica sul-americana, na medida em que se constituiu em um organismo regional de defesa sem a presença dos Estados Unidos, ao mesmo tempo em que se evidenciava uma política externa brasileira de caráter mais ofensivo, pela qual o país buscava assumir uma postura de elemento catalisador na América do Sul.

\section{"Por uma dissuasão extrarregional": discursos}

Analisaremos nesta seção discursos de ex-ministros ${ }^{5}$ da Defesa do Brasil que estiveram à frente da pasta na primeira metade da década atual, tendo como foco principal a ideia de estratégia de "dissuasão extrarregional". Conforme veremos mais adiante, tal estratégia aparecerá 208 em documentos e discursos como um novo paradigma de defesa para a região, em que as relações entre os países sul-americanos seriam pautadas pela cooperação e, consequentemente, pela superação de antigas hipóteses de conflito. Por outro lado, tal estratégia sugeria a ideia de uma defesa coletiva contra supostas ameaças oriundas de potências extrarregionais.

Essa ideia passou a ser difundida no âmbito sul-americano especialmente após a criação do CDS, em dezembro de 2008. A primeira autoridade a anunciar essa estratégia foi o ex-ministro da Defesa Nelson Jobim que, por diversas vezes, fez referência ao aprofundamento do processo de cooperação no campo da defesa como "fator de dissuasão extrarregional". Para ele, o mais correto seria usar a expressão “dissuasão" nas relações do continente sul-americano em

\footnotetext{
${ }^{5} \mathrm{O}$ mandato de Nelson Jobim se estendeu de 25 de junho de 2007 a 4 de agosto de 2011. Celso Amorim permaneceu no cargo de 4 de agosto de 2011 a $1^{\circ}$ de janeiro de 2015.
} 
relação aos países que não integram esse território, haja vista a necessidade de se pensar uma estratégia para uma região que se caracteriza por ser a detentora de inúmeras riquezas naturais. Por outro lado, em relação aos países da região, a estratégia brasileira não seria dissuasória, mas cooperativa (Jobim, 2010b).

Se levada adiante, a proposta provocaria uma alteração radical na forma como a concepção estratégica de dissuasão vinha historicamente sendo imaginada pelo Brasil, nem tanto no sentindo de sua finalidade, conforme significado clássico da expressão - induzir o adversário à desistência de suas pretensas intenções pelo receio que teria de uma consequente represália (Bobbio, 2002) -, mas principalmente no significado de sua nova escala territorial. Se antes o foco eram os vizinhos (nível internacional), agora passaria a ser os atores externos à região (nível extrarregional).

Jobim apresentou oficialmente a proposta de uma estratégia comum de dissuasão regional durante a III Reunião Ordinária do Conselho de Defesa Sul-Americano (CDS), realizada em Lima, Peru, no dia 12 de maio de 2011. Na ocasião, o ministro brasileiro lembrou aos participantes que o continente sul-americano possui algumas das principais riquezas (os aquíferos Guarani e da Amazônia, proteínas animais e vegetais, além das fontes renováveis de geração de energia) que, com o aumento da população mundial e o esgotamento de parte desses bens, podem ser objeto da cobiça de outros povos. Para Jobim, "o futuro vai exigir do subcontinente uma estratégia comum de dissuasão", e acrescentou: "Será que estaremos preparados para isso?" (Rabelo, 2011).

O discurso de Jobim põe foco na preocupação com a defesa dos recursos estratégicos da América do Sul. Para ele, o cenário geopolítico das próximas décadas sugere sérios desafios à preservação dissuasória da economia 
sul-americana (Jobim, 2011). Para Jobim, ${ }^{6}$ o aumento da cooperação entre os países da região, a construção de uma identidade regional de defesa, baseada na cooperação, e a criação de uma organização de defesa coletiva, por si só, constituiriam fatores de dissuasão extrarregional.

Nelson Jobim foi substituído no Ministério da Defesa por Celso Amorim em agosto de 2011. Já no início de setembro do mesmo ano, Amorim deixava claro em seus discursos que adotaria uma visão semelhante à de seu antecessor sobre a América do Sul. Em um discurso proferido em 5 de setembro de 2011, na Escuela de Defensa Nacional, em Buenos Aires, intitulado La Comunidad de Seguridad Sudamericana, Amorim (2011) passou a tratar a região como uma comunidade de segurança. Em seu discurso, primeiro questiona se o conceito de anarquia é apropriado para descrever a relação entre os Estados da região, que, segundo ele, seria baseada no trabalho coletivo sob o signo da integração. Em seguida, sugere: "O 210 conceito de 'comunidade de segurança' me parece muito mais adequado à realidade e, sobretudo, aos objetivos que temos para a América do Sul" (Amorim, 2011, tradução nossa).

No mesmo discurso, Amorim buscou estabelecer uma relação direta entre "comunidade de segurança" e "dissuasão extrarregional”:

O que desejamos - e buscamos com empenho - é a constituição de uma comunidade de segurança sulamericana, suscetível de eliminar definitivamente o conflito armado entre os países da região. Essa estratégia cooperativa pretende fomentar relações políticas intensas entre os países da América do Sul, que sirvam, elas mesmas, como elemento de dissuasão extrarregional (Amorim, 2011, tradução nossa).

\footnotetext{
${ }^{6}$ Discurso proferido no seminário sobre o Livro Branco de Defesa Nacional (LBDN), em 28 de abril de 2011, em Porto Alegre (RS). Disponível em: <https://goo.gl/ ygfRx0>. Acesso em: 11 maio 2011.
} 
Tal como seu antecessor, ao mesmo tempo que se utilizava de um discurso idealista para promover a ideia de uma comunidade de segurança regional, Amorim mostrava-se realista ao deixar transparecer seu ceticismo pela ideia de uma estrutura de defesa regional. Ao propor a necessidade de desenvolvimento de uma dissuasão sul-americana, reconhece os diferentes imperativos geopolíticos presentes no interior da região. Para ele, cada Estado sul-americano possui diferentes capacidades e imperativos geoestratégicos. Nesse sentido, apesar de reconhecer a "enorme" margem de convergência que aproxima os países da região, Amorim buscava deixar claro que "não quero com isso defender a existência de um modelo único de defesa - algo que o Brasil jamais faria em vista de sua tradicional oposição a esquemas do tipo one size fits all' (Amorim, 2011, tradução nossa).

Em outros discursos, Amorim reafirmava a necessidade de adotar posturas cooperativas nas relações entre os países da região, reforçando o "cinturão de boa vontade" criado no entorno geopolítico brasileiro para garantir a nossa segurança (Amorim, 2012a). Dirigindo-se a militares chilenos durante a aula magna da Escola Militar do Chile, em 23 de março de 2012, Amorim aproxima ainda mais as ideias de comunidade de segurança e dissuasão compartilhada:

Estou convencido de que a América do Sul caminha para ser uma comunidade de segurança, no sentido que o cientista político Karl Deutsch conferiu a esta expressão: uma comunidade de estados soberanos entre os quais a guerra é impensável como método de solução de controvérsias. Quanto à dissuasão, queremos desenvolvê-la de forma compartilhada com a América do Sul. (Amorim, 2012b)

Em outra ocasião, ao discursar sobre o novo regionalismo sul-americano durante seminário da Unasul, em Quito, Equador, realizado no dia 10 de maio de 2012, 
Amorim se utiliza das ideias de Andrew Hurrell para dizer que "há dois momentos no processo de integração: o primeiro em que a região passa a exercer um papel definidor nas relações entre os estados [...] e o segundo quando a região passa a formar a base organizadora de políticas na região para inúmeras questões" (Amorim, 2012c). Ainda conforme o então ministro, o "segundo momento" sugerido por Hurrell estaria começando a ocorrer na região: "Passamos a formular a base da política de defesa da região, buscando soluções consensuadas para inúmeras questões. As medidas de fomento da confiança e da segurança são excelentes exemplos" (Amorim, 2012c).

\section{Discursos no âmbito do CDS}

O Centro de Estudos Estratégicos de Defesa do Conselho de Defesa Sul-Americano (CEED - CDS) da Unasul passou a funcionar em maio de 2011, com sede na Argentina. O

212 CEED objetiva desenvolver um pensamento estratégico no âmbito regional, tendo como ponto de partida a definição e identificação dos interesses regionais, buscando contribuir para a coordenação e a harmonização das políticas de defesa na América do Sul (CDS, 2010).

Como veremos a seguir, os discursos analisados na seção anterior parecem ter encontrado terreno fértil no âmbito do CDS, especialmente o que diz respeito à ideia de defesa (coletiva) dos recursos estratégicos da região.

Segundo Forti, primeiro diretor do CEED, os recursos naturais têm sido considerados no âmbito do CDS como o fator central do que tem sido denominado "interesse regional sul-americano" (Forti, 2013). Deve-se ressaltar que antes mesmo da criação do CEEC, a ideia de proteção dos recursos naturais como elemento de identidade regional já vinha sendo discutida. Durante o $1^{\circ}$ Encontro Sul-Americano de Estudos Estratégicos, realizado na Escola Superior de Guerra, no Rio de Janeiro, em novembro de 2009, Javier 
Ponce (então Ministro da Defesa do Equador e presidente do CDS), ao proferir a palestra Perspectivas para o Conselho de Defesa Sul-Americano, afirmou que sem desconsiderar a importância de outros tipos de ameaças, como o narcotráfico, a principal preocupação de defesa na região diz respeito à salvaguarda de seus recursos naturais.

Alfredo Forti define a categoria "interesse regional" como "o conjunto dos fatores comuns, compatíveis e/ou complementares do interesse nacional de cada um dos países membros da Unasul" (Forti, 2013, p. 2, tradução nossa). Assim, para Forti, "a partir da perspectiva da defesa, a adoção do conceito de interesse regional nos leva a propor um nível estratégico superior ao nacional para articular nesse nível o que o CDS propõe como uma identidade sul-americana em defesa" (Forti, 2013, p. 2, tradução nossa). Considerando-se os conceitos discutidos na primeira seção, pode-se aqui fazer um paralelo entre "interesse regional" e o tipo "para fora" de comunidade de segurança. Para ele, nada ilustraria melhor o conceito de "interesse regional" que recursos naturais estratégicos compartilhados pelos países da região e que se constituem em "bens comuns aos doze países da Unasul” (Forti, 2013, p. 2).

Os debates no âmbito do CEED/CDS giram em torno da defesa dos recursos naturais da região que, por serem escassos, tornam-se naturalmente estratégicos para quem os possui. Seriam exemplos desses recursos o petróleo, os recursos hídricos, a biodiversidade etc.

$\mathrm{O}$ fato de os recursos naturais estarem disseminados entre os países da região, em muitos casos atravessando as fronteiras políticas que os separam, e considerando as fragilidades de defesa inerentes a países em desenvolvimento, conduz o pensamento estratégico regional a considerar a necessidade de unir esforços. Assim, de acordo com esse pensamento, nenhum Estado da região teria condições de, sozinho, estabelecer uma estrutura de defesa efetiva de seus ativos estratégicos, o que só poderia ser alcançado por 
meio de esforços cooperativos em prol de uma estratégia de alcance regional (Forti, 2013).

A estratégia regional para a proteção dos recursos naturais desenvolvida no CEED/CDS inclui, naturalmente, a defesa como uma de suas dimensões. A questão que se coloca é: como se deve estruturar um sistema de defesa regional no que diz respeito a essa matéria? Para Forti, a resposta para essa pergunta já estaria em marcha e expressaria, em sua visão, a própria razão de existência do CDS: "Um esquema regional cooperativo fundado em uma dupla categoria: cooperação 'para dentro' e dissuasão 'para fora"' (Forti, 2013, p. 15, tradução e grifos nossos).

Forti cita como avanços na cooperação para dentro o abandono de velhas hipóteses de conflito entre Estados sul-americanos; a realização de exercícios combinados; o desenvolvimento de doutrinas conjuntas em matéria de operações de paz, assistência humanitária e atenção a desastres 214 naturais; entre outros (Forti, 2013, p. 16).

No que diz respeito à dimensão para fora, o discurso adotado pelo CDS parece sugerir, inevitavelmente, a ideia de defesa coletiva. Segundo Forti, "implica que nossas capacidades regionais nos campos da defesa e militar devem concentrar-se e fundirem-se em uma sô" (Forti, 2013, p. 17, grifos $\mathrm{e}$ tradução nossos).

Por meio de um documento intitulado La defensa y los recursos naturales em Suramérica, Forti (2014) sugere discutir "como" operacionalizar de forma concreta a categoria dissuasão para fora. Em outras palavras, como pensar estruturas de defesa que deem substância a uma estratégia de defesa extrarregional? A resposta de Forti a sua pergunta parece contundente: "Como instrumento tangível para operacionalizar a 'dissuasão para fora', cremos que chegou o momento de propor a criação de uma 'Força Militar Sul-Americana (FMS) ', sob dependência direta das autoridades políticas de nossos países" (Forti, 2014, p. 20, tradução nossa). 


\section{Dissuasão extrarregional sul-americana: viabilidade?}

Recorramos aos aspectos teóricos apresentados na primeira seção para discutirmos a viabilidade de implementação de uma estratégia coletiva de dissuasão extrarregional na América do Sul.

A primeira questão posta diz respeito a quem seriam os atores a serem dissuadidos. Em outras palavras, a quem a "mensagem dissuasória sul-americana" se destinaria?

Aparentemente, poderiam ser considerados "destinatários" em potencial qualquer unidade política situada fora da América do Sul e que, de alguma forma, representasse ameaça à integridade territorial dos países do subcontinente. Isso poderia ser representado por uma grande potência ou por um conjunto de países poderosos, sem a necessidade de se estabelecer nominalmente o inimigo. Assim, uma "messagem dissuasória sul-americana" seria enviada a qualquer potência extrarregional que representasse ameaça ao patrimônio natural da região.

Uma segunda questão diz respeito ao grau de integração regional: possuiria a América do Sul unidade política necessária para estabelecer uma estratégia de dissuasão coletiva?

Como vimos anterioremente, qualquer estratégia responde necessariamente a uma proposição política. A ideia de unidade política na América do Sul, porém, é controversa. A própria criação do CDS parecia obedecer a diferentes "agendas políticas".

\footnotetext{
${ }^{7}$ Medeiros Filho (2009) identificava naquele contexto três agendas: bolivariana, mercosulina e brasileira. Para o autor, a agenda bolivariana corresponderia às iniciativas do então presidente Hugo Chávez de implementação do "Socialismo do Século XXI", que se caracterizava por mesclar tendências socialistas, populistas, nacionalistas e, principalmente, antiamericanas. A agenda mercosulina se referia à ideia de construção, sob uma perspectiva liberal, de um organismo sul-americano com a finalidade de alavancar o comércio intrarregional e proporcionar a manutenção dos regimes democráticos. A agenda brasileira estaria relacionada a um suposto projeto geopolítico brasileiro para o subcontinente. Os esforços brasileiros para
} 
A persistência de estoques de desconfianças entre países da região e as diferentes "agendas" regionais constituem travas ao avanço de projetos de integração regional, denotando um contexto em que não estão dadas as condições políticas para o estabelecimento de uma estratégia dissuasória de base regional na América do Sul.

Tal cenário torna questionável a ideia de "fundir-se em uma só" as capacidades regionais de defesa para a proteção do "interesse regional" diante de ameaças de terceiros. Aliás, uma preocupação constante dos representantes brasileiros, desde que se cogitou pela primeira vez a ideia do CDS, foi justamente descaracterizar qualquer possibilidade de se estruturar um organismo de defesa coletiva na região.

De fato, a oposição a quaisquer arranjos de defesa no campo operacional foi uma constante nos discursos de Jobim durante a campanha em defesa da criação do CDS. Em seus discursos, o então ministro sempre procurava deixar claro que "em nenhum momento foi considerada a constituição de uma aliança militar no sentido clássico, ou outro tipo de acordo que possa, a priori, articular ações no plano operacional.." (Jobim, 2009, p. 8, tradução nossa). Mais recenteme, o ex-ministro da Defesa Nelson Jobim $^{8}$ revelou que, durante as tratativas para criação do CDS, o presidente Chávez tinha uma ideia de criar uma Otan do Sul. Porém, em visita realizada à Venezuela, ele acabou convencendo Chávez de que esse não era o sentido do projeto.

Por outro lado, há que se considerar que cogitar o estabelecimento de uma estratégia de dissuasão regional sugere,

liderar o processo de integração regional no campo da defesa e da segurança seriam parte desse projeto.

${ }^{8}$ Declaração feita durante a mesa redonda "Incertezas globais e perspectivas do Brasil", desenvolvida no dia 6 de agosto de 2013 como parte do VII Encontro Nacional da Associação Brasileira de Estudos de Defesa, realizada em Belém, Pará, entre os dias 4 e 8 de agosto de 2013 . 
inevitavelmente, a necessidade de se considerar um conjunto de recursos (meios), incluindo capacidades militares, que possibilitem a sua implementação. Não há como conceber estratégias sem atribuir-lhes os recursos necessários à sua concretização. Em última instância, aliás, o fator mais contundente e explícito de uma estratégia de dissuasão diz respeito ao componente militar, sem o qual não haverá dissuasão (Lima, 2010).

Do ponto de vista de um modelo ideal, parece pouco plausível a eficácia de uma estratégia dissuasória regional que não esteja respaldada por uma política de defesa coletiva.

\section{Conclusão}

Pelo exposto, conclui-se que, dadas as condições de instabilidades políticas presentes no cenário regional, a ideia de uma estratégia coletiva de dissuasão sul-americana mostra-se pouco viável. Aparentemente, a proposta constitui-se em uma aposta para o futuro, tendo por base a percepção compartilhada na região de que as riquezas naturais do subcontinente são cobiçadas e podem ser ameaçadas por potências extrarregionais, o que sugere, então, a ideia de estratégia de defesa conjunta.

O cenário construído no âmbito do CEED/CDS sugere que a América do Sul, pelos recursos estratégicos de que dispõe, terá papel-chave no cenário mundial das próximas décadas. A concretização de uma estratégia dessa natureza envolveria um longo percurso de necessário avanço na cooperação e integração política. A vontade política compartilhada deve, nesse caso, ser maior que os custos (inclusive financeiros) que poderão advir de uma empreitada dessa natureza.

O aumento da pressão por recursos naturais nas próximas décadas e a presença de novas potências no entorno geopolítico sul-americano - especialmente a 
China - tenderão a abreviar a percepção regional sobre a necessidade de uma defesa coletiva. A percepção compartilhada sobre um inimigo comum, entretanto, não é condição suficiente para a construção de uma política comum de defesa. $\mathrm{O}$ ambiente interno de estabilidade política é fator fundamental para o avanço em busca política de defesa compartilhada.

Para o Brasil, considerando seu desejo de liderança regional e sua clássica postura de oposição a qualquer arranjo operacional de defesa coletiva para a região, o tema "estratégia de dissuasão extrarregional" lhe impõe duas questões: 1) como avançar na criação de uma estratégia regional de defesa sem transformar o CDS em um instrumento de defesa coletiva?; e 2) como elaborar uma estratégia de dissuasão extrarregional mantendo, ao mesmo tempo, um ambiente cooperativo entre os países da região?

De fato, a consolidação de uma estratégia regional de 218 defesa dependerá, em muito, do comportamento do Brasil como líder regional. É lícito imaginar que um processo de "regionalização" seja entendido por um país - neste caso, o Brasil - como um passo necessário à realização de seu projeto de desenvolvimento nacional no qual a ideia de segurança coletiva constitua complemento de sua segurança nacional.

O Brasil parece ciente de que a sua projeção internacional passa necessariamente pela construção de uma parceria estratégica com o seu entorno. Tal empreitada envolve o fomento de mecanismos de confiança mútua. O ex-ministro Jobim parecia ter clara essa situação quando definia o "grande dilema" enfrentado pelos responsáveis pelas políticas de defesa: "projetar no futuro a força que, a um só tempo, garanta capacidade dissuasória em contextos cambiantes e que respalde os interesses internacionais do país, sem fomentar percepções de agressão em outros estados" (Jobim, 2010c). 


\section{Oscar Medeiros Filho}

é bacharel e licenciado em Geografia pela Universidade Federal de Mato Grosso do Sul (1995). Possui mestrado em Geografia Humana (2004) e doutorado em Ciência Política pela Universidade de São Paulo (2010). Lecionou Geografia, Antropologia, Sociologia e Política na Escola Preparatória de Cadetes do Exército (1996-2010). Foi professor das Cadeiras de Relações Internacionais e Geografia da Academia Militar das Agulhas Negras (2011-2012). Foi professor e pesquisador nos programas de pesquisa e pós-graduação do Instituto Meira Mattos da Escola de Comando e Estado-Maior do Exército (2013-2015). Atual Coordenador do Núcleo de Estudos Prospectivos do Centro de Estudos Estratégicos do Exército.

\section{Bibliografia}

AMARAL, P. S. A. 2004. A conferência dos exércitos americanos e as atuais posições do exército brasileiro, no contexto das relações internacionais. Trabalho de Conclusão de Curso - Escola de Comando e Estado-Maior do Exército. Rio de Janeiro.

AMORIM, C. 2011. La Comunidad de Seguridad Sudamericana. Discurso do Ministro da Defesa na Escuela de Defensa Nacional, Buenos Aires, 5 de setembro.

2012a. Defesa: um diálogo nacional. Apresentação do Ministro de Estado da Defesa na Câmara dos Deputados. In: II SEMINÁRIO Estratégia Nacional de Defesa: Política Industrial e Tecnológica, Brasília, 15 de fevereiro.

2012b. Estratégia de defesa do Brasil e da América do Sul. Aula magna do Ministro da Defesa na Escola Militar do Chile, Santiago, 23 de março. . 2012c. Palestra do Ministro da Defesa. In: SEMINÁRIO O

Pensamento Estratégico na Unasul, Quito, Equador, 10 de maio. BOBBIO, N. 2002. Dicionário de Política. Brasília: UnB. v. 1.

CONSELHO DE DEFESA SUL-AMERICANO. 2010. Estatuto do Centro de Estudos Estratégicos de Defesa do Conselho de Defesa Sul-Americano. Guaiaquil: CDS.

DEUTSCH, K. W. 1966. Integración y formación de comunidades políticas: análisis sociológico de experiencias históricas. Buenos Aires: Intal. 1982. Análise das relações internacionais. 2. ed. Tradução de Maria Rosinda Ramos da Silva. Brasília: UnB. 
FORTI, A. W. 2013. El papel de la Defensa en una estrategia suramericana para el aprovechamiento de los recursos naturales. In: CONFERENCIA Suramericana: Visiones hacia una Estrategia Suramericana para el Aprovechamiento de los Recursos Naturales, Unasur, Caracas, Venezuela, 27 a 30 de mayo. 2014. La Defensa y los recursos naturales en Suramerica: aportes para una estrategia regional. In: CONFERENCIA la Defensa y los Recursos Naturales, CDS, Buenos Aires.

JOBIM, N. 2009. Discurso de abertura. Apresentação no I Encuentro Suramericano de Estudios Estratégicos (I ESEE), Rio de Janeiro, 11 a 13 de novembro. . 2010a. El Consejo de Defensa Suramericano y el desarrollo de medidas de fomento de la confianza y seguridad: una breve reflexión del punto de vista brasileño. In: CONSEJO DE DEFENSA SURAMERICANO. Cuadernos de Defensa 2: Confianza y seguridad en América del Sur. Quito: Abya-Yala. 2010b. Palestra de abertura. Apresentação na VII Conferência do Forte de Copacabana, Rio de Janeiro, 3 de novembro. . 2010c. Palestra de abertura. Apresentação no seminário Segurança Internacional: Perspectivas Brasileiras, Fundação Getúlio Vargas, Rio de Janeiro, 26 de março. 2011. Discurso do Ministro da Defesa. Apresentação em comemoração dos 200 anos da Academia Militar das Agulhas Negras, Resende, 16 de abril.

LIMA, R. N. O. 2010. Faces de estratégia da dissuasão. Padeceme, n. 22. MARTINS FILHO, J. R. 2006. As Forças Armadas brasileiras e o Plano Colômbia. In: CASTRO, C. C. P. (org.). Amazônia e defesa nacional. Rio de Janeiro: FGV. pp. 13-29.

MEDEIROS FILHO, O. 2009. Geografia política sul-americana e percepções das agências de defesa. In: ARAÚJO, M. C. S.; SOARES, S. A.; SVARTMAN, E. (orgs.). Defesa, Segurança Internacional e Forças Armadas: II Encontro da ABED. Campinas: Mercado de Letras. 2010. Entre a cooperação e a dissuasão: políticas de defesa e percepções de militares dos exércitos da América do Sul. Tese (Doutorado em Ciência Política) - Universidade de São Paulo, São Paulo.

RABELO, L. G. 2011. Brasil e Argentina defendem adoção de estratégia comum de dissuasão por países sul-americanos. Brasília: Ministério da Defesa. Disponível em: <https://goo.gl/K1W5Pv>. Acesso em: 25 maio 2011. SILVEIRA, R. M. 2003. Segurança e Defesa: a visão do Exército Brasileiro. Palestra proferida no Ministério da Defesa, Brasília, 10 de setembro. VIEGAS FILHO, J. 2003. Defesa: cooperação nacional e internacional. Palestra proferida na Unicamp, Campinas, 3 de julho. 


\section{A CONSTRUÇÃO DE UMA IDENTIDADE REGIONAL DE DEFESA PARA A AMÉRICA DO SUL: AGENDAS E DESAFIOS}

\section{OSCAR MEDEIROS FILHO}

Resumo: O texto visa analisar a trajetória de construção de uma estratégia regional de defesa para a América do Sul que ganhou força com a constituição, em 2008, do Conselho de Defesa Sul-Americano (CDS). Discute-se a viabilidade do modelo de "estratégia regional de dissuasão", recentemente incorporada a discursos de autoridades de defesa na região. A hipótese levantada no texto mostra que o estabelecimento de compromissos estratégicos para o CDS conduzirá, inevitavelmente, ao debate sobre instrumentos de defesa coletiva, incluindo temas como integração de capacidades militares, o que nos parece pouco viável para uma região marcada pela instabilidade política e pela coexistência de agendas geopolíticas diversas. Partindo do conceito de comunidade de segurança, apresentaremos um breve histórico da trajetória sul-americana em matéria de cooperação em defesa. O surgimento do conceito de "dissuasão regional" será analisado por meio da análise de discursos de autoridades no âmbito do CDS. Ao final, discutiremos a viabilidade ou não de uma estrutura de "dissuasão regional" para a América do Sul.

Palavras-chave: América do Sul; Comunidade de Segurança; Dissuasão Extrarregional.

\section{THE CONSTRUCTION OF A REGIONAL IDENTITY OF DEFENSE FOR SOUTH AMERICA: CHALLENGES AND AGENDAS}

Abstract: The paper analyzes the process of constitution of the regional defense strategy for South America that culminated with the creation of the South American Defense Council (CDS), in 2008. In this paper, we discuss the "extra-regional deterrence" model, present in speeches of authorities from the region. Our hypothesis is that the 
establishment of strategic commitments to the CDS will inevitably lead to the debate on collective defense instruments, including topics such as integration of military capabilities, which seems impractical for a region marked by geopolitical instability. Based on the concept of security community, we present a brief history of the defense cooperation process in the South American. The emergence of the concept of "regional deterrence" will be analyzed considering the discourse of public authorities from the sphere of the CDS. Finally, we discuss the chance of success of a structure of "regional deterrence" for South America.

Keywords: South America; Security Community; Extra-regional Deterrence.

Recebido: 04/01/2015 Aprovado: 11/11/2016 